\title{
OS OBJETOS TUTORES E SUA IMPORTÂNCIA NA CLÍNICA PSICANALÍTICA DE CRIANÇAS COM AUTISMO
}

\section{TUTOR-OBJECTS AND THEIR IMPORTANCE IN THE PSYCHOANALYTIC CLINIC OF CHILDREN WITH AUTISM}

Talita Arruda Tavares

E-mail para correspondência: talita.psicologia@yahoo.com.br

Audrey Setton Lopes de Souza

Demora

Algumas coisas demoram. moram mais tempo, saem do tempo. nos observam, incuriosas e um pouco displicentes. poderiam perguntar-se: será que ele (ela) vai aguentar esperar? mas nem isso se perguntam. aguardam aconchegadas na morada dos dias, dos meses, dos anos, até chegar sua vez de acontecer. não têm pressa. deixam-nos aflitos e talvez até se divirtam com nossa ansiedade. é preciso olhar para elas, lá no alto da montanha, na rachadura de uma rocha, no fundo da terra onde elas costumam ficar até chegarem aqui, e fitá-las calmamente, no máximo, murmurar: está

bem coisa. eu espero você.

Quando nada está acontecendo, Noemi Jaffe. 


\section{RESUMO}

O presente trabalho tem como objetivo apresentar o papel dos objetos tutores como ferramenta importante para a clínica psicanalítica de crianças com autismo. Autores como Winnicott, Rodulfo e Guerra defendem que o brincar acompanha pari passu o desenvolvimento subjetivo, de forma que as perturbações que aparecem na estruturação psíquica do bebê podem ver-se refletidas no desenvolvimento da capacidade para o brincar. Essas dificuldades são observadas de forma clara nas crianças com autismo, que apresentam tanto a incapacidade para o brincar quanto perturbações em sua constituição subjetiva. Dessa maneira, o tratamento psicanalítico visa o desenvolvimento do brincar dessas crianças, tendo em vista seus efeitos constitutivos. Partimos de duas vinhetas clínicas que ilustram a importância da criação compartilhada do objeto tutor pela dupla analítica na clínica do autismo, seja por meio da transformação do objeto autístico ou de propostas de continuidades para os movimentos estereotipados. Pudemos observar como o conceito de objeto tutor mostra-se um recurso valioso para a clínica psicanalítica do autismo.

Palavras-chave: Psicanálise da Criança; Constituição Subjetiva; Brincar; Autismo; Setting.

\section{ABSTRACT}

This paper aims to discuss the role of tutor objects as an important tool for the psychoanalytical clinical treatment of autistic children. Authors such as Winnicott, Rodulfo and Guerra state that playing progresses alongside emotional development, and thus disturbances in the babies' psychical structure development will reflect in his capacity to play. These difficulties are clearly observed in children with autism, who present both the incapacity to play and the disturbances in their subjective constitution. Thus, psychoanalytical treatment aims at developing the capacity to play in these children, bearing in mind its aforementioned effects to healthy subjective constitution. Two clinical scenes illustrate the importance of creation of the tutor object by both the analyst and the patient, might it be through the transformation of an autistic object into a tutoring object or through the proposition of activities transforming the stereotypical behavior into meaningful and communicative behavior. The author considers the tutoring object as a valuable resource to psychoanalytical clinical practice with autistic children.

Keywords: Children Psychoanalysis; Subjective development; Play; Autism; Clinical setting. 


\section{APRESENTAÇÃO}

Observando a brincadeira de seu neto Ernest com o carretel, Freud percebeu que o brincar, além de ser o passatempo favorito entre as crianças, apresentava uma função importante. Através do jogo do Fort/Da, como ficou conhecida a brincadeira de Ernest de mandar o carretel embora e trazê-lo de volta, Freud identificou um exercício de elaboração psíquica, através da repetição da brincadeira, que ajudava o neto a dominar a situação desagradável de separação da mãe. Ernest brincava de se separar da mãe e de trazê-la de volta, podendo, através do jogo, esperar tranquilamente o reencontro com a mãe.

Encenado a partir da escolha de um substituto para a figura da mãe (o carretel), o jogo do Fort/Da apresentava-se como precursor do desenvolvimento da capacidade de simbolização na criança. A partir disso, Freud chegava à importante conclusão de que no brincar havia uma importante função constitutiva para as crianças.

Tal perspectiva preparou o terreno para aprofundamentos teóricos posteriores por parte de outros psicanalistas, como Winnicott, Ricardo Rodulfo ${ }^{1}$ e Victor Guerra. Esses autores puderam ir além das proposições de Freud, compreendendo que o brincar constitutivo já podia ser observado nos primeiros meses de vida do bebê - ou seja, muito antes do desenvolvimento da capacidade de simbolização - e que esse brincar ocorria no espaço privilegiado da relação intersubjetiva entre a mãe e o bebê².

Tendo isso em vista, o brincar na clínica psicanalítica passou a ocupar outro lugar na relação analítica, já que não poderia ser tomado apenas como expressão de conteúdos inconscientes do pequeno paciente, mas principalmente se apresentava como o motor da constituição subjetiva. Essa proposição abria caminhos para o tratamento psicanalítico de crianças que apresentavam prejuízos significativos na estruturação psíquica - o trabalho do analista diante dessas crianças era o de desenvolver a capacidade para o brincar (Winnicott, 1975).

Considerando esse pano de fundo, a proposta deste trabalho trata da especificidade da clínica psicanalítica de crianças com autismo, apresentando algumas possibilidades para o desenvolvimento do brincar na relação entre a dupla analista-paciente.

Lei materna e objeto tutor: contribuições de Victor Guerra sobre a importância da relação intersubjetiva entre a dupla mãe-bebê.

1 Rodulfo (1990).

2 Na minha dissertação de mestrado (TAVARES, T. 2016) pude abordar mais extensamente o brincar constitutivo presente na relação intersubjetiva entre a mãe e o bebê. 
Victor Guerra (2015) prioriza o conceito de lei materna para tratar da importância da presença da mãe no processo de constituição subjetiva do bebê. Segundo o autor, a base da relação entre a dupla é a sintonia afetiva que a mãe estabelece com o pequeno, ajudando-o a integrar novas experiências, a criar um espaço intersubjetivo de trocas afetivas, de comunicação não-verbal, de espontaneidade, de criatividade e de abertura para as relações sociais. Para Guerra, a mãe empenhada nos cuidados com seu filho, estabelece a lei materna do encontro intersubjetivo, definida como

Uma forma (através de processos empáticos) de regular (como faz toda a lei) algum aspecto do funcionamento do sujeito, para possibilitar a convivência com os outros. E a "lei materna do encontro" é para mim um princípio organizador da vida afetiva com o bebê como sujeito incipiente (Guerra, 2015, p. 6, tradução nossa).

A lei materna abarca três grandes funções. A primeira constitui-se como o respeito ao ritmo próprio do bebê, que pode ser definido como aquilo que emerge do contato de um adulto com um bebê no princípio da subjetivação - "o encontro de olhares, a voz, o corpo, o movimento põe em jogo elementos rítmicos que pautam sensivelmente o encontro e desencontro" (Guerra, 2013, p. 6).

$\mathrm{O}$ segundo aspecto da lei materna diz respeito às funções de espelhamento, tradução e transformação de vivências afetivas do bebê - funções relacionadas a um aspecto trabalhado por Winnicott (1967a), a saber, o rosto da mãe como precursor do espelho para o bebê. De acordo com Winnicott "a mãe está olhando para o bebê e o que ela aparenta está relacionado com aquilo que ela vê ali (Winnicott, $1967 \mathrm{a}$, p. 151, tradução nossa ${ }^{3}$ ). Assim, a mãe reflete aquilo que ela vê no bebê: reflete através de sua expressão fácil, pelas rugas de preocupação, pelos traços de alegria, pelo olhar de surpresa e de interesse etc. Por sua vez, a expressão facial da mãe oferece ao bebê a imagem daquilo que ele está sentindo, em um momento do desenvolvimento emocional primitivo em que ainda não há diferenças entre eu e não-eu para o bebê. A imagem do próprio bebê refletida no rosto da mãe auxilia-o na constituição do verdadeiro self. A capacidade de refletir os estados emocionais do filho, por meio da sintonia afetiva, faz com que a mãe possa identificar-se com a angústia do bebê, assim como com outros estados emocionais. Por meio da identificação a mãe pode traduzir as emoções desagradáveis do bebê porque ela também sente aquilo, mas, diferentemente do filho,

3 No original: In other words, the mother is looking at the baby and what she looks like is related to what she sees there (p. 151). 
conta com os próprios recursos psíquicos para transformar a angústia em algo mais tolerável, tanto para ela quanto para o bebê - transformação que ele ainda não é capaz de fazer.

O terceiro e último aspecto da lei materna pode ser definido como a abertura ao terceiro na relação mãe-bebê. A entrada do terceiro diz respeito à introdução da função paterna, à apresentação de objetos, à abertura à palavra, ao eixo presença-ausência e à capacidade de simbolização. Essa abertura ao terceiro ocorre através da disposição lúdica da mãe, que apresenta a possibilidade do contato mediado pela palavra (não corporal) e por objetos para o bebê. Assim, a triangulação da relação mãe-bebê se coloca como interdição estruturante, de modo que o bebê é lançado a outras possibilidades de relação com o mundo, não restritas ao corpo da mãe ou à sua presença física (Guerra, 2015, p. 11).

Para melhor compreender a importância da abertura ao terceiro e a introdução de objetos pela mãe na relação com a criança, Guerra (2010b) apresenta o conceito de objeto tutor. Segundo o autor, os objetos tutores podem ser definidos como quaisquer objetos que despertem o interesse do pequeno, contanto que a mãe perceba esse interesse e possa introduzi-los de forma lúdica ao bebê. Através de sua disponibilidade lúdica, a mãe faz com que aquele objeto possa ganhar um sentido, uma história, uma cantiga, criando uma brincadeira compartilhada com o filho. Essa distância entre a mãe e o bebê preenchida pelo objeto tutor cria as condições necessárias para que o pequeno possa vivenciar as primeiras formas de simbolização em presença materna (Roussillion, 2003 apud Guerra, 2013). A simbolização em presença prepara o bebê, de uma maneira não traumática, para a simbolização na ausência materna - a simbolização propriamente dita - presente no jogo do carretel de Ernest.

Ainda falando a respeito do objeto tutor, Guerra (2010b) nos remete à definição de dicionário para a palavra tutor:

1) Vara ou estaca que se finca junto a uma planta para a manter direita em seu crescimento.

2) Exercer tutela: que guia, ampara ou defende. Autoridade a quem, na ausência paterna ou materna, confere-se os cuidados de pessoas ou bens de alguém que, por ser menor de idade ou por outro motivo, não tem completa capacidade civil (p. 9, tradução nossa).

O objeto tutor, como o papel da estaca para a planta, oferece sustentação para que o bebê possa se distanciar da mãe-terra à medida que se desenvolve. "Assim, a estaca teria uma função muito importante para que a planta não se incline para os lados ou inclusive que não se curve em direção à mãe-terra" 
(2010b, p. 9, tradução nossa). A segunda definição marca a responsabilidade do tutor na ausência dos pais, já que é quem assume os cuidados com o filho - e aqui podemos incluir também os cuidados em relação à constituição intersubjetiva na ausência dos pais.

Dessa maneira, os objetos tutores favorecem a criação de um espaço privilegiado onde o bebê poderá se interessar por algo diferente da mãe e também poderá estabelecer um tipo de comunicação íntima com ela, não atravessada pelo contato corporal. É também nesse intervalo entre a dupla que ocorrerá a construção da alternância entre ausência e presença materna, colocando o bebê em contato com a alteridade e levando-o ao desenvolvimento da capacidade de simbolização.

\section{OBJETOS TUTORES NA CLÍNICA PSICANALÍTICA DE CRIANÇAS COM AUTISMO: UMA APROPRIAÇÃO A PARTIR DA PRÁTICA CLÍNICA}

Nossa experiência clínica nos levou a conferir grande importância ao conceito de objeto tutor para a clínica psicanalítica do autismo, tendo esse conceito se revelado um valioso recurso para a instauração de um espaço constitutivo entre os dois sujeitos (analista e paciente).

Em geral, as crianças com autismo apresentam uma constituição do eu extremamente fragmentada e vulnerável, que as impede de entrar em contato com a alteridade, haja vista que esse encontro poderia ser extremamente desorganizador. As estereotipias, as repetições, o isolamento e os objetos autísticos ajudam a criança a se proteger do contato com o mundo externo, anulando qualquer tipo de percepção da alteridade. Nesse contexto, a presença empática e sensível do analista pode favorecer o estabelecimento de outras formas de sustentação vital para a criança através do brincar, que não coloquem em xeque a frágil constituição do eu, como a criação compartilhada dos objetos tutores.

A seguir veremos duas vinhetas que ilustram a relevância do conceito de objeto tutor para essa clínica. Apresentaremos duas cenas clínicas onde os objetos tutores puderam ser criados através do brincar compartilhado entre a dupla terapêutica. A primeira situação clínica trata da ideia de que os objetos tutores podem se estabelecer em meio às estereotipias e às repetições. O segundo fragmento nos permite discutir a complexa e delicada tarefa de diferenciação entre o objeto autístico e o objeto tutor.

\section{A criação do objeto tutor em meio à repetição e às estereotipias}

Gabriel iniciou o atendimento psicoterapêutico com quase quatro anos de idade. Diagnosticado com autismo, ainda não tinha desenvolvido a fala, usava fraldas, babava incessantemente e era extremamente agitado. Du- 
rante os primeiros meses de atendimento, quando ia buscá-lo na sala de espera, Gabriel corria pelos corredores até entrar na sala de atendimento, alcançava muito rapidamente a caixa de brinquedos e se divertia em arremessá-los no chão, sem discriminar um objeto do outro, parecendo buscar ouvir o barulho produzido quando os objetos caiam no chão.

Ao longo do nosso primeiro ano de atendimento, fomos descobrindo possibilidades de nos encontrarmos no meio do caminho. Conseguimos estabelecer uma brincadeira em que ele jogava os objetos pela sala, eu me posicionava de maneira a estar onde os objetos caiam e os recebia como se fossem endereçados a mim. Em seguida, eu os jogava de volta para ele. Em outra brincadeira, Gabriel jogava um objeto no fundo da sala, longe de nós. (Talvez, Gabriel tivesse a intenção de que eu não alcançasse o brinquedo antes de ele cair no chão, provavelmente para ouvir aquele barulho). Nessas situações, eu o convidava para uma aposta de quem chegaria primeiro ao brinquedo depois da largada dada pela contagem "1,2,3 e já". Depois dessa cena se repetir inúmeras vezes, Gabriel passou a jogar o objeto no fundo da sala e me dar sua mão, como um convite à corrida atrás do brinquedo. Ao som da largada, íamos correndo de mãos dadas ao encontro do brinquedo.

Os objetos arremessados estavam a serviço do comportamento autístico de Gabriel de ouvir incessantemente o ruído produzido quando eles tocavam o chão. Mesmo ocupado com suas estereotipias, Gabriel demonstrava certa abertura para o brincar compartilhado através das breves propostas de continuidade dos movimentos estereotipados. Aproveitando essa abertura, a terapeuta se posicionava como receptora dos objetos arremessados ou convidava Gabriel para a corrida em busca do brinquedo lançado ao fundo da sala após a contagem regressiva.

$\mathrm{Na}$ clínica psicanalítica de crianças com autismo, cabe ao analista, respeitando o tempo e a singularidade daquela criança, introduzir pequenas interrupções no ritmo autocentrado das estereotipias. As interrupções e as propostas de continuidade dos movimentos estereotipados são fundamentais na medida em que se traduzem em apostas feitas pelo terapeuta de que do outro lado da brincadeira há um sujeito a advir. Essa aposta acontece através de intervenções lúdicas do analista que podem abrir espaço para o surgimento do novo e da criatividade, aspectos fundamentais para o estabelecimento de uma relação intersubjetiva entre terapeuta e criança. Por sua vez, o convite ao brincar pode ocorrer através da criação dos objetos tutores, ou seja, objetos que se apresentam a partir da invenção do brincar compartilhado pela dupla analítica.

$\mathrm{Na}$ vinheta acima, acompanhamos como os objetos lançados de forma repetitiva e estereotipada ao fundo da sala puderam se tornar um estímulo para a brincadeira de corrida entre terapeuta e criança. Nesse sentido, as intervenções 
puderam criar outro lugar para esses objetos, que passam a compor um espaço lúdico, da fantasia e do brincar compartilhado entre Gabriel e a terapeuta. Assim, a dupla criava de forma conjunta a função de objeto tutor para aqueles brinquedos que outrora compunham um comportamento autístico. E lá está o sujeito da vinheta acima, convocando a terapeuta para a corrida em busca do brinquedo em meio às estereotipias!

Agora, passemos a outra situação clínica em que observamos que a função de objeto tutor se estabelece a partir da exploração repetitiva e estereotipada da criança em relação a um objeto, apresentando uma dimensão complexa em relação à forma com que o objeto tutor pode aparecer na clínica do autismo.

\section{Objeto subjetivo, objetivo autístico ou objeto tutor?}

Felipe apresentava um grau de autismo bastante grave. Tinha quase quatro anos, ainda não havia desenvolvido a fala, demonstrava grande apatia e indiferença pelo ambiente ou pelas pessoas, não se atraía por nenhum brinquedo e permanecia por quase todas as sessões andando em círculos pela sala. Esfregava incessantemente uma mão na outra ou friccionava entre as palmas das mãos a fraldinha da chupeta, as meias ou seu chinelo. Ficava completamente absorto por essa estimulação sensorial. Podia permanecer por muito tempo ocupado com essas estimulações, completamente indiferente a mim, à sala e aos brinquedos.

Depois de alguns meses de tratamento, encontrávamo-nos numa situação em que eu tentava chamar sua atenção para um xilofone, tocando-o com uma baqueta e cantando uma cantiga infantil. Felipe andava em círculos pela sala e às vezes me olhava de canto de olho até que, em um determinado momento, aproximou-se de mim, pegou a baqueta do xilofone que eu havia oferecido e prosseguin pelo seu caminho em círculos, friccionando a baqueta nas palmas das mãos. Assistia à minha tentativa fracassada de fazê-lo se interessar pelo xilofone, mas, ao mesmo tempo, e pela primeira vez, testemunhava sua iniciativa de segurar algo nas mãos. Depois desse dia, frequentemente passou a pegar a baqueta na caixa de brinquedos tão logo entrava na sala, e permanecia friccionando-a nas mãos enquanto se movimentava em círculos.

Percebi que ali, na estereotipia daquele movimento com as mãos que explorava a baqueta, talvez houvesse uma abertura para a exploração de novos brinquedos - outros instrumentos musicais? Assim, apresentei a ele um tamborzinho de madeira, sustentado por uma espécie de vareta mais grossa, com duas cordas em cada lado, tendo em suas extremidades uma bolinha que batia no tamborzinho emitindo um som quando o instrumento 
era posto em movimento por meio da fricção das palmas das mãos - o mesmo movimento que Felipe realizava com a baqueta de forma estereotipada. O interesse por esse novo objeto foi imediato em Felipe, principalmente quando compreendeu que poderia tocar o tamborzinho por meio do movimento, já conhecido, de fricção com as mãos.

Pela primeira vez, depois de meses de atendimento, Felipe estava segurando um brinquedo, percebendo-o como um todo, se interessando pelo som produzido por aquele instrumento. O seu interesse pelo tamborzinho foi tanto que, quando a sessão chegou ao fim, pela primeira vez não pôde se separar do brinquedo sem demonstrar um enorme sofrimento por isso. Saiu da sala em lágrimas, no meu colo, demonstrando sua intensa frustração mordendo-me no rosto.

Inicialmente, o trabalho terapêutico com Felipe delineou-se em torno da apresentação de objetos - uma tentativa de chamá-lo ao contato afetivo e instigar alguma curiosidade pelo mundo que o cercava. Por muito tempo, observávamos certo interesse pelos objetos apresentados, através de um olhar distante, oblíquo e rápido de Felipe em direção à terapeuta, mas nunca em direção aos objetos ${ }^{4}$. Essa situação se repetiu inúmeras vezes até que, em um determinado momento, Felipe finalmente se aproximou da mesa em que se encontrava a terapeuta e pegou a baqueta do xilofone. O ambiente terapêutico estável, aliado à constante reapresentação dos objetos, parece ter favorecido o gesto de Felipe.

$\mathrm{O}$ ato de pegar a baqueta nos remete ao primeiro momento do jogo da espátula de Winnicott ${ }^{5}$, em que a criança finalmente pega a espátula, podendo criá-la como seu objeto subjetivo a partir da confiança em relação ao ambiente em que se encontra. Segundo o autor, nos primeiros momentos do desenvolvimento emocional primitivo, os objetos só existem para o bebê como extensão de sua própria existência, pois sustentam a ilusão do controle onipotente sobre o mundo. Ainda de acordo com Winnicott (1968) o bebê cria o objeto, mas o objeto precisa estar lá, esperando para ser criado e tornar-se um objeto psicoenergeticamente investido.

Retomando a situação clínica acima, notamos que a baqueta parece ter sido incorporada por Felipe, tornando-se uma extensão do seu próprio corpo. Tal incorporação não nos causa surpresa, tendo em vista que Felipe parecia ainda precisar de experiências de continuidade com o ambiente, dado que ainda não era capaz de entrar em contato com a alteridade.

4 Ao contrário da maioria das crianças com autismo, Felipe olhava diretamente para a terapeuta, mas não olhava em direção aos objetos.

5 Remetemos o leitor ao texto de Winnicott (1941). 
No entanto, a vinheta clínica acima não fala de um bebê, mas de uma criança com autismo. Assim, poderíamos nos perguntar a respeito da natureza do objeto incorporado por Felipe: consideramos a baqueta um objeto subjetivo ou um objeto autístico?

Retomando algumas definições conceituais sobre o objeto autístico e o objeto subjetivo, poderemos identificar uma semelhança entre eles, já que tanto um quanto o outro se apresentam como prolongamentos do eu, exercendo para a criança a função de negação da diferenciação entre eu e não-eu. Em contrapartida, a maior diferença entre o objeto subjetivo e o objeto autístico diz respeito ao fato de que a criança em posse do seu objeto subjetivo pode se abrir para o brincar primitivo com a mãe - que ainda não é o brincar compartilhado, nem o brincar apoiado nos fenômenos transicionais, mas o brincar que não exige da criança a percepção da existência de outra pessoa além de si mesma. Já o objeto autístico sustenta a indiferenciação entre eu e não-eu, blindando a criança de qualquer contato com o mundo externo, que pode ser sentido como extremamente desorganizador. Assim, o objeto autístico obtura qualquer tipo de diferença entre o eu e o não-eu; diferença que poderia arremessar a criança numa vivência da perda de si mesma. Diferentemente do objeto autístico, o objeto subjetivo não blinda o bebê dos acontecimentos fora dele, mas sim permite o contato com o mundo externo através da ilusão de controle onipotente, sem colocar em risco a própria existência do bebê.

Tendo em vista essas definições, uma observação rápida da situação clínica poderia nos levar a deduzir que a baqueta se estabelece como um objeto autístico, já que é explorada de forma estereotipada e mantém Felipe indisponível para a troca com a terapeuta. No entanto, uma análise mais demorada levanta uma questão complexa e delicada. No caso de Felipe - que não pegava nenhum objeto e mostrava-se alheio aos acontecimentos à sua volta - o estabelecimento do suposto objeto autístico não ocorre de forma aleatória ou indiferente em relação ao ambiente em que ele estava inserido: o gesto de pegar a baqueta acontece dentro de um contexto terapêutico que não deve ser ignorado. Felipe não elege qualquer objeto da sala para se tornar o suposto objeto autístico; ele pega justamente a baqueta que estava sendo apresentada a ele pela terapeuta. Tendo isso em vista, o gesto em direção à baqueta pode ser compreendido, no mínimo, como um interesse de Felipe pelo objeto ou ainda, de forma mais otimista, como uma resposta ao convite de interação feito pela terapeuta ${ }^{6}$. Seja por uma razão ou por outra,

6 A afirmação de que, no mínimo, Felipe apresentou um interesse pela baqueta só pode ser sustentada como um fato a posteriori. Sabemos pela continuidade da vinheta que Felipe interessou-se pelo tamborzinho, o que nos permite fazer uma suposição de que ele tinha uma atração especial pelos instrumentos musicais. Isso pôde ser manifestado primeiramente através do interesse pela baqueta, seja por ela mesma ou pelo som que ela produzia em contato com o xilofone. 
Felipe não se mostra completamente alheio aos acontecimentos ao seu redor. Esses apontamentos nos permitem colocar sob suspeita a qualificação da baqueta como objeto autístico.

Mas, se então não podemos aceitar sem questionamentos a baqueta como objeto autístico, também não podemos compreendê-la como objeto subjetivo, já que Felipe não cria a baqueta sozinho, como acontece com a espátula no jogo proposto por Winnicott ${ }^{7}$ : a baqueta é apresentada a Felipe pela terapeuta, que estimula seu interesse ao som do xilofone. Isso nos leva à possibilidade de compreendermos a baqueta como uma espécie de objeto tutor, a partir do aspecto de criação compartilhada entre Felipe e a terapeuta, mesmo considerando que o uso que Felipe fez da baqueta ainda não pudesse ser compartilhado.

Nesse sentido, identificamos no gesto de Felipe uma pequena abertura para a dimensão do brincar mediada por um objeto tutor, em meio às estereotipias e à aparente indiferença em relação à terapeuta.

Dessa forma, a baqueta mostra a complexidade com que os objetos podem ser compreendidos na clínica psicanalítica do autismo, opondo-se às deduções reducionistas e deterministas. A vinheta nos mostra ainda que a exploração repetitiva e disfuncional de um objeto nem sempre quer dizer que esse objeto é autístico, assim como as estereotipias nem sempre estão relacionadas a um comportamento esvaziado de sentido ou de intenção.

\section{CONSIDERAÇÕES FINAIS}

$\mathrm{Na}$ clínica psicanalítica de crianças e, mais especificamente, na clínica de crianças com autismo, o analista muitas vezes ocupa a função materna estruturante diante de um sujeito em processo de constituição. A sintonia afetiva do analista em relação à criança se apresenta como a base para o trabalho terapêutico. A partir da capacidade do analista de sentir os mesmos afetos que a criança, ele é capaz de ajudá-la a entender e nomear suas emoções e angústias, introduzindo assim o campo da palavra, dando nome ao que até então era inominável. Por esse caminho, o analista pode conhecer e reconhecer (eventualmente pode ajudar a criar) o ritmo próprio daquele paciente, identificando o momento da aproximação, o tempo de espera e o instante de propor desafios. $\mathrm{O}$ analista, sintonizado afetivamente e atento aos interesses oblíquos e sutis da criança por algum objeto, pode apresenta-los à criança - assim como a mãe introduz os objetos tutores ao filho - propondo novas formas de exploração.

\footnotetext{
7 Winnicott orientava a mãe a não dar a espátula à criança, assim como também a não a incentivar a pegar a espátula. A ideia era que a criança pegasse a espátula quando se sentisse preparada para isso.
} 
O analista pode ser aquele que se encanta com certa beleza dos movimentos estereotipados produzidos pela criança, mas também pode ser aquele que interrompe o brincar estereotipado com uma surpresa; pode ser aquele que faz as próprias mãos dançarem ao ritmo de uma cantiga, mostrando para a criança que o contato com os objetos e com as pessoas não exige tanta rigidez. $\mathrm{O}$ analista pode ser aquele que, valendo-se de sua disposição lúdica, transforma o objeto estático, pobre e aprisionante, em um instrumento musical, em algo que se movimenta, em um personagem vivo com histórias para serem contadas, em qualquer coisa que a surpreenda e que a leve para a dimensão da fantasia e do lúdico. Nesse sentido, o analista cria as condições, juntamente com a criança, para que um objeto autístico possa ser transformado em objeto tutor. A partir dessas breves e insistentes intervenções lúdicas, o analista pode testemunhar, lenta e pacientemente, o nascimento de um sujeito através do brincar constitutivo.

Desse modo, o tratamento psicanalítico é um lugar privilegiado e potente para dar continuidade à constituição subjetiva, e nesse processo a criação dos objetos tutores se mostra como um recurso muito valioso.

Trazendo novamente a metáfora da estaca para falar do objeto tutor, poderíamos imaginar que o analista desempenha a função de jardineiro que, cuidando do crescimento e atento às características particulares de cada planta, determina o lugar adequado para fincar a estaca na terra. Em outras palavras, o trabalho analítico consiste em oferecer à criança com autismo outros meios de sustentação que possam colocar em movimento sua constituição subjetiva, a partir de experiências integradoras e estruturantes. Assim como a epígrafe que abre esse capítulo, cabe ao analista aguardar pacientemente os movimentos constitutivos de seu paciente, pois como acontece com o crescimento de uma planta, leva tempo e saem do nosso tempo.

\section{REFERÊNCIAS}

Freud, S. (1920). Além do princípio do prazer. In: Edição Standard Brasileira das Obras Psicológicas Completas de Sigmund Freud, 18. Rio de Janeiro: Imago, 2006.

Guerra, V. (2010b). Simbolizacion y objeto en la vida psíquica: los objetos tutores. No prelo. Guerra, V. (2015). Palavra, ritmo e jogo: fios que dançam no processo de simbolização. Revista de Psicanálise da Sociedade de Porto Alegre, 20(3).

Guerra, V. (2015). El ritmo y la ley materna en la subjetivacion, y en la clinica in-fantil. Revista Uruguaya de Psicóanalisis, 120, 133-152.

Tavares, T. (2016). O brincar na clínica psicanalítica de crianças com autismo. Dissertação de Mestrado. Instituto de Psicologia da Universidade de São Paulo, São Paulo, SP.

Winnicott, D. (1967a). Mirror-Role of Mother and Family in Child Development. In: Playing and Reality. London: Routledge, 2005.

Winnicott, D. (1968). O uso de um objeto e o relacionamento através de identificações. In: Explorações psicanalíticas: D.W. Winnicott. Porto Alegre: Artmed, 1994.

Winnicott, D. (1975). O brincar \& a realidade. Rio de Janeiro, RJ: Imago Editora. 